\title{
Does systemic heparin reduces thrombosis rate of radiocephalic fistula: A double-blinded randomized study
}

\author{
Karthigesu Aimanan ${ }^{1 *}$, Mohamad Azim Mohd Idris ${ }^{1}$, Lenny Suriyani Safri ${ }^{1}$, Putera Mas Pian², Tan Yee Ling ${ }^{3}$, Chew Loon Guan ${ }^{3}$ and \\ Hanafiah Harunarashid ${ }^{1}$ \\ ${ }^{1}$ Department of Surgery, National University of Malaysia, Malaysia \\ ${ }^{2}$ Department of Vascular Surgery, Kuala Lumpur Hospital, Malaysia \\ ${ }^{3}$ Department of Vascular Surgery, Serdang Hospital, Malaysia
}

\begin{abstract}
Background/Objective: The National Kidney Foundation Kidney disease outcomes quality initiative guidelines suggest that the creation of more native arteriovenous fistulas (AVFs) would improve the quality of life of end stage renal failure patients. However, the ability to comply with this suggestion is affected by the failure rate of AVFs mainly due to thrombosis. Heparin is a well-accepted treatment to prevent thrombosis in general but has not been suggested in arteriovenous fistula. This study was conducted to investigate the effect of intraoperative systemic heparin on the thrombosis rate and associated morbidities over a duration of six weeks.

Methods: Ninety patients who were planned recipients of a radiocephalic fistula, presenting between July 2015 and July 2016, were randomized equally into a heparin and a placebo group. The drug was administered intraoperatively before clamping the artery. Patients were followed up for a duration of six weeks in vascular clinic.

Results: A total of 88 patients completed the study, with 44 patients per group. The group who received intraoperative systemic heparin showed a significant reduction in early $(9.1 \%$ versus $25 \%, \mathrm{p}=0.05)$ and late $(9.1 \%$ versus $27.3 \%, \mathrm{p}=0.03)$ thrombosis rate, with a better maturation rate $(86.4 \%$ versus $68.2 \%$, $\mathrm{p}=0.04)$. There was no statistically significant difference between the groups in terms of hematoma and infection.

Conclusion: This study revealed the beneficial outcomes, and no adverse effects, associated with intraoperative administration of heparin in radio cephalic fistula Better maturation was demonstrated in the heparin group at the six-week follow-up. These beneficial outcomes should be taken into consideration in the future to change the practice of AVF creation.
\end{abstract}

Abbreviations: AVF: Atriovenous fistula; RCF: Radiocephalic fistula; ESFF: End stage renal failure

\section{Introduction}

\section{Epidemiology}

The prevalence of end-stage renal failure (ESRF) is increasing worldwide. In 2010, the estimated prevalence of chronic kidney disease in the United States was $16.8 \%$, while in Asia, the prevalence was reported to range from $12.1 \%$ to $17.5 \%$. [1-4] In Malaysia, the incidence and prevalence of patients with ESRF on dialysis has increased from 325 per million population in 2001 to 762 per million population in 2009 [5].

\section{Native arteriovenous fistulas}

Dialysis is an essential element of ensuring a better quality of life for ESRF patients throughout the world. The ground-breaking article by Brescia and Cimino in 1966 revolutionized the creation of the vascular access, and the Cimino fistula was soon used in almost all dialysis patients [6]. In current practice, a native arteriovenous fistula (AVF) is the preferred choice of vascular access due to its longevity, and the decreased risk of infection compared to peritoneal and catheter directed dialysis. In 2006, the National Kidney Foundation's Kidney Disease Outcomes Quality Initiatives (KDOQI) guidelines for vascular access called for an increase in native AVF placement to improve patients' quality of life and survival.

\section{Native arteriovenous failure and thrombosis}

Although the creation of vascular access is necessary for hemodialysis, maintenance of a well-functioning vascular access remains the most challenging problem for hemodialysis therapy. A recent meta-analysis demonstrated a $20-50 \%$ primary failure rate for native AVF [7]. Proper access-site selection, improved surgical techniques, and appropriate management of complications are the main factors for long-term success.

Thrombosis is a well-documented cause of AVF failure. Primary failure of native AVFs occurs as a result of thrombosis within the first few weeks following the surgical creation (early thrombosis), causing inadequate maturation of the vein [8]. AVF has the highest incidence of thrombosis in the early period (30 days postoperative) [9].

\section{Heparin use in radiocephalic fistulas}

Based on the literature, thrombosis can be effectively prevented by heparin. Heparin acts as an anticoagulant, preventing the formation

Correspondence to: Karthigesu Aimanan, Department of Surgery, National University of Malaysia, Malaysia, E-mail: karthi_abim@yahoo.com

Key words: Radiocephalic fistula thrombosis, primary fistula failure, heparin in radio cephalic fistula, maturation of fistula

Received: October 02, 2017; Accepted: November 06, 2017; Published: November 09, 2017 
of clots and the extension of existing clots within the blood. Although the KDOQI guidelines are very clear regarding the sequence in which access sites should be used, as well as the timing of access creation, the guidelines do not address the use of systemic anticoagulation during the access creation.

Ravari et al. and Farzaneh [10,11] have advocated the use of intraoperative heparin during dialysis access creation. However, D'Ayala et al. and Bhomi et al. $[12,13]$. reported a risk of intraoperative bleeding and no beneficial effect in patency.

These studies focused on native AVF. A recent meta-analysis of the literature found an increased risk of failure of radiocephalic fistulas (41\%) compared with brachiocephalic fistulas (15\%) over a six-week period [14].

In this study, we aim to compare the effect of systemic heparin on the early thrombosis rate of radiocephalic fistulas. We hope that the use of systemic heparin intraoperatively will reduce the thrombosis rate among radiocephalic fistula patients. This will be a useful adjunct to increase the creation of radiocephalic fistulas, consistent with the KDOQI guidelines.

\section{Objectives}

The primary objective of this study was to assess the thrombosis rate in radiocephalic fistula patients given intraoperative heparin. The secondary objectives were to evaluate postoperative complications in patients given intraoperative heparin, and to evaluate hemodynamic changes in radiocephalic fistula patients given intraoperative heparin.

\section{Methods}

\section{Sample design}

This study was a prospective double blinded randomized study conducted within the Department of Vascular Surgery, Serdang Hospital, Selangor, Malaysia.

\section{Patient enrolment}

Patients were permitted to participate in the research after receiving vein mapping with a color Doppler ultrasound, which was performed by trained personnel, according to the inclusion criteria. Consent to participate in the study was obtained in the clinic. Patients were admitted to the ward on the scheduled day for surgery.

\section{Randomization and administration of heparin/saline}

Upon admission to the ward, patients were given two envelopes to choose from. Envelope A contained heparin 80 unit $/ \mathrm{kg}$ and envelope B contained saline $10 \mathrm{ml}$ (this information was only available to the assigned medical officer preparing the drugs, until the study analyses had been completed). On the day of surgery, the drug or saline was prepared by the assigned medical officer. The surgery was carried out according to standard practice. The drugs were administered intraoperatively through a branula on the opposite hand, after crossclamping of arteries. A period of three minutes was given before proceeding with anastomosis.

\section{Postoperative follow-up assessment}

Patients were discharged after surgery according to standard practice. They were given verbal and written advice to return to the hospital or to contact the investigator should any problems arise in relation to the fistula. The patients were reviewed in the vascular clinic one, four, and six weeks post-surgery. The week one assessment was carried out by the investigator, using the designated assessment form, to check for wound infection, hematoma, and thrombus. After four weeks, the investigator assessed the maximum diameter at the fistula site, flow rate, and thrombosis. After six weeks, the maturity of the fistula was assessed. We used the standard criteria according to KDOQI for maturation assessment: fistula flow rate $>600 \mathrm{ml} / \mathrm{min}$, the diameter of vein $>6 \mathrm{~mm}$, the length of vein $>6 \mathrm{~cm}$, and skin thickness $<$ $6 \mathrm{~mm}$. Ultrasound was performed by trained personnel using a colour Doppler ultrasound.

\section{Sample size}

The calculated sample size of the study was 90 patients, inclusive of an expected drop-out rate of $10 \%$. The risk/prevalence difference taken was $27 \%$, with a two-sided significance level of $95 \%$. The power of the study was $80 \%$.

\section{Selection criteria}

Inclusion criteria: Participants were ESRF patients or chronic kidney disease (CKD) approaching end stage patients, referred to the vascular clinic for dialysis access creation. ESRF was defined as complete loss of renal function. CKD approaching end stage was defined as CKD stage five, with plans to start dialysis. Other inclusion criteria included:

\section{Minimum age of 18 years;}

2. Vessel diameter more than $2 \mathrm{~mm}$;

3. Radiocephalic fistula only.

\section{Exclusion criteria:}

1. Patients on warfarin therapy;

2. Patients with a platelet count $<100 \times 10^{9} / \mathrm{L}$;

3. History of coagulopathy;

4. Pregnant patients;

5. Patients with active gastrointestinal bleeding.

Approval for this study was obtained from the UKM Medical Centre Clinical Research Ethics Committee (UKM 1.5.3.5/244/FF-2015277). Informed written consent was obtained from the patients after explaining the purpose and procedures of the study. Confidentiality was strictly maintained throughout the study.

\section{Results}

\section{Patient demographics}

A total of 90 patients were included in the study based on our sample size calculation; 45 patients were included in each study group. One patient in the heparin study group was lost to follow-up after the first week, and one patient in the placebo group passed away two weeks after surgery (secondary to fluid overload). In total, 88 patients completed the study. describe the patient demographics and surgical factors of the study population, respectively.

The mean age of the patients in the heparin group was 54.6 years with a standard deviation (SD) of +13.5 years; in the placebo group, mean age was 54.6 years with a SD of +12.5 years. There was a higher male to female ratio in both the heparin and placebo groups; $62 \%$ and $57.8 \%$ of males, respectively.

Diabetes mellitus and hypertension were the most prevalent comorbidities in the study groups. In the heparin group, 40 patients 
(88.9\%) were diabetic; 41 patients $(91.1 \%)$ in the placebo group were diabetic. All patients in the placebo group were hypertensive while only $40(88.9 \%)$ in the heparin group were hypertensive. Statistical analysis of patient demographic factors, including age, gender, and underlying comorbidities, revealed no statistically significant differences.

The mean duration of ESRF in the heparin group was 13.45 months with a SD of +10 months, whereas in the placebo group it was 14.5 months with a SD of +20 months, $\mathrm{p}=0.37$. The number of patients with a previous history of dialysis was also similar in both groups.

\section{Surgical factors}

Surgical factors that were analyzed in this study were the duration of surgery and the level of experience of the surgeons. Surgeons who had performed more than 100 cases were defined as seniors, and less than 100 cases were defined as juniors. Twenty-three of the fistulas in the heparin group (51.1\%) were created by junior surgeons and 22 (48.9\%) were created by senior surgeons. In the placebo group, 21 fistulas (46.7\%) were created by junior surgeons, and 24 (53.3\%) fistulas were created by senior surgeons (Tables $1 \& 2$ ). Statistical analysis showed both groups were also identical in term of duration of surgery and level of surgeons' experience.

\section{Outcomes}

Table 3 shows the outcomes of the study population. Three patients $(6.8 \%)$ in the heparin group and three patients $(6.8 \%)$ in the placebo group had an infection at the fistula site which was treated with oral antibiotics. Hematoma at the fistula creation site was noted in eight patients (18.2\%) in the heparin group and five patients (13.3\%) in the placebo group. In all patients, hematoma was managed conservatively.

Table 1. Descriptive summary of patient demographic factors for each study group.

\begin{tabular}{|l|c|c|c|c|}
\hline \multirow{2}{*}{ Age (Mean/SD) } & & \multicolumn{2}{|c|}{ Study group } & \multirow{2}{*}{ Significance } \\
\cline { 2 - 4 } & & Heparin & Placebo & \\
\hline Dialysis & Yes & $23.64( \pm 13.35)$ & $56.64( \pm 12.58)$ & $0.51^{\mathrm{a}}$ \\
\hline Gender & Male & $28(62.2 \%)$ & $23(51.1 \%)$ & $1.00^{\mathrm{b}}$ \\
\hline $\begin{array}{l}\text { Duration of ESRF (Month) } \\
\text { (Mean/SD) }\end{array}$ & Female & $17(37.8 \%)$ & $19(42.2 \%)$ & $0.07^{\mathrm{b}}$ \\
\hline Previous fistula & & $13.45(10.04)$ & $14.50(20.22)$ & $0.37^{\mathrm{a}}$ \\
\hline Diabetes & & $13(28.9 \%)$ & $12(26.7 \%)$ & $0.81^{\mathrm{b}}$ \\
\hline Hypertension & & $40(88.9 \%)$ & $41(91.1 \%)$ & $1.00^{\mathrm{c}}$ \\
\hline Peritoneal dialysis & & $6(13.3 \%)$ & $8(17.8 \%)$ & $0.56^{\mathrm{b}}$ \\
\hline Ischaemic heart disease & & $2(4.4 \%)$ & $1(2.2 \%)$ & $1.00^{\mathrm{c}}$ \\
\hline Peripheral vascular disease & & $14(31.1 \%)$ & $12(26.7 \%)$ & $0.64^{\mathrm{b}}$ \\
\hline $\begin{array}{l}\text { Patients on antiplatelet } \\
\text { therapy }\end{array}$ & & $4(8.9 \%)$ & $7(15.6 \%)$ & $0.52^{\mathrm{c}}$ \\
\hline
\end{tabular}

a Mann Whitney U Test

${ }^{\mathrm{b}}$ Chi Square Test

${ }^{\mathrm{c}}$ Fisher Exact Test

Table 2. Descriptive summary of surgical factors for each study group.

\begin{tabular}{|c|c|c|c|c|}
\hline & & \multicolumn{2}{|c|}{ Study group } & \multirow{2}{*}{ Significance } \\
\hline & & Heparin & Placebo & \\
\hline $\begin{array}{l}\text { Duration of surgery } \\
\text { (minutes) (Mean/SD) }\end{array}$ & & $64.22( \pm 9.22)$ & $63.93( \pm 12.71)$ & $0.99^{\mathrm{a}}$ \\
\hline \multirow[t]{2}{*}{$\begin{array}{l}\text { Level of surgeon } \\
\text { experience }\end{array}$} & Junior & $23(51.1 \%)$ & $24(53.3 \%)$ & \multirow[t]{2}{*}{$0.83^{\mathrm{b}}$} \\
\hline & Senior & $22(48.9 \%)$ & $21(46.7 \%)$ & \\
\hline Dilatation & & $8(17.8 \%)$ & $10(22.2 \%)$ & $0.60^{\mathrm{b}}$ \\
\hline
\end{tabular}

a Mann Whitney U Test

${ }^{\mathrm{b}}$ Chi Square Test
Table 3. Comparison of outcomes between heparin and placebo group.

\begin{tabular}{|c|c|c|c|}
\hline \multirow{2}{*}{} & \multicolumn{2}{|c|}{ Study group } & \multirow{2}{*}{ Significance } \\
\cline { 2 - 3 } & Heparin & Placebo & \\
\hline Thrombus after one week & $4(9.1 \%)$ & $11(25.0 \%)$ & $0.05^{\mathrm{a}}$ \\
\hline Thrombus after four weeks & $4(9.1 \%)$ & $12(27.3 \%)$ & $0.03^{\mathrm{a}}$ \\
\hline Infection & $3(6.8 \%)$ & $3(6.8 \%)$ & $1.00^{\mathrm{a}}$ \\
\hline Hematoma & $8(18.2 \%)$ & $5(13.3 \%)$ & $0.53^{\mathrm{b}}$ \\
\hline Maturation & $38(86.4 \%)$ & $30(68.2 \%)$ & $0.04^{\mathrm{b}}$ \\
\hline
\end{tabular}

a Fisher Exact Test

${ }^{\mathrm{b}}$ Chi Square Test

Statistical analysis of these two outcomes revealed no significant difference between the heparin and placebo group.

Thrombus at the first postoperative week was found in four patients (9.1\%) in the heparin group and 11 patients $(25.0 \%)$ in the placebo group. At the fourth postoperative week, the number of thrombus in the heparin group remained the same whereas in the saline group, there was one additional thrombus detected. This difference in thrombus incidence at the 1 st week and 4 th week was statistically significant between the groups.

A total of six radiocephalic fistulas (13.6\%) failed to mature in the heparin group compared to $14(31.8 \%)$ patients in the placebo group. Thrombosis was the cause for maturation failure in four out of six cases in the heparin group (66\%), and 12 out of 14 cases in the placebo group (86\%).

\section{Discussion}

\section{Superiority of arteriovenous fistula}

AVF has been recommended by KDOQI as the preferred method for dialysis access to maintain long term patency and avoid the risk of catheter-related complications. Despite this, there has been ongoing concern regarding the patency of AVFs. Patency of AVFs has been reported to range from 50-60\% [15-17]. George et al [18]. have addressed factors, such as increasing age, presence of diabetes, smoking, peripheral vascular disease, predialysis hypotension, and vessel characteristics, as directly influencing AVF patency.

\section{Evidence on heparin use}

Thrombosis has been a well-documented cause for the primary failure of native AVFs. A literature review of previous studies [1013] on the use of systemic intraoperative anticoagulants to prevent thrombosis reported variable findings. Ravari et al. and Farzaneh $[10,11]$. have advocated towards the use of intraoperative heparin during dialysis access creation. D'Ayala et al. and Bhomi et al. [12,13]. have shown an increased risk of bleeding intraoperatively and no beneficial effect on patency. Due to variation in the reported outcomes, heparin has not been widely used during fistula creation. In the current study, we have improved upon the limitations described in previous papers, to describe the benefits and associated morbidities of using heparin for fistula creation.

\section{Limitations of previous studies}

Nguyen and colleagues [19] reported that brachiocephalic fistulas were superior in terms of maturity and patency rate, compared to radiocephalic fistulas. These differences were supported by the smaller caliber of radiocephalic vessels. In order to analyze the effect of heparin, the type of native vascular access should be standardized. All the previous studies, except Bhomi [13] et al., included all types of native arteriovenous fistulas in their research. In our study, we have only selected radiocephalic fistulas to avoid this selection bias. 


\section{Effect of heparin on thrombosis}

The role of heparin in the creation of radiocephalic fistulas is to reduce the formation of thrombi caused by hypercoagulability secondary to turbulent blood flow or shear stress [20]. Following administration, heparin stays in the blood for at least 1-2 hours, which helps in prevention of early thrombus. Prevention of early thrombus indirectly maintains the patency and assists the fistula maturity. Our study has shown that heparin does reduce early and late thrombus formation, three times more than the placebo group. This highlights the importance of heparin in native AVF creation. In addition, there have been few studies demonstrating the effect of heparin on the vessel wall and cellular blood elements in isolation from their effects on blood coagulation and other plasma systems [21]. This can also be a contributing factor to the observed favorable outcomes in the heparin group patients.

\section{Concern regarding adverse effects of heparin}

Intraoperative bleeding has been documented in studies by D'Ayala and Bhomi $[12,13]$. We believe the assessment of bleeding in minor surgery, such as fistula creation, is very subjective. None of these studies described in detail the method of assessment of bleeding. In addition, non-blinding of the surgeons and their attitude towards or against an intervention may directly be transferred to participants, in term of perioperative bleeding [22]. In this study, we also blinded the surgeons to avoid any treatment bias.

Wang et al. [23]. conducted a double blinded randomized study and reported a higher number of hematomas in the heparin group; however, this was not statistically significant, $p=0.60$. The power of this study was limited by the smaller sample size (46 patients). On the contrary, in our paper, we found no significant difference in infection and hematoma rate between the heparin and placebo groups. These results confirm the safe use of heparin in the creation of radiocephalic fistulas [24] raised concerns in his meta-analysis regarding the monitoring of baseline coagulation studies, and the effects of administered anticoagulation in the intervention group in laboratory studies. The anticoagulant effect of heparin following administration of an $80 \mathrm{U} / \mathrm{kg}$ bolus dose usually lasts for a maximum of two hours. Laboratory monitoring does not confer any cost-benefit outcome in this group of patients. However, we did analyze clinical outcomes, such as hematoma and wound infection in our treatment group patients, which can directly be ascribed to bleeding-related complications. Our data show no significant differences between the heparin and placebo group.

\section{Effect of heparin on the maturation of fistulas}

Maturation should be the final assessment of the fistula creation. None of the previously published studies on heparin usage in AVFs have analyzed maturation as their final outcome. We believe it is an important final clinical outcome that should be given emphasis. In this study, we randomized patient age and gender to reduce the confounding effects, and to show the absolute effect of heparin. Our analysis showed better maturation rate in the group given intraoperative heparin. By reducing the early thrombosis rate, heparin indirectly improved the maturation rate in our study.

\section{Limitations}

In our study, patients were followed up for six weeks following surgery, corresponding to our objective to assess the primary patency and maturation. However, an extended follow-up for a year might provide concrete evidence on the long-term outcome of patients with intraoperative heparin administration. Further, in future, we hope more centers can participate in this study to assess the efficacy of intraoperative systemic heparin. This will help to eliminate any possible biases due to variation in vessels among populations, and surgery techniques among centers.

\section{Conclusion}

This study has demonstrated that the use of heparin efficiently reduces the thrombosis rate in small caliber native AVFs (radiocephalic), with no statistically significant adverse effects. The improved clinical outcome also improved the hemodynamics of the fistula, and resulted in a superior maturation rate compared to the non-intervention group. Based on our randomized double blinded study, we recommend a wide change of practice to use of intraoperative systemic heparin in native AVF creation.

\section{Declarations}

\section{Ethics approval and consent to participate}

Approval for this study was obtained from the UKM Medical Centre Clinical Research Ethics Committee (UKM 1.5.3.5/244/FF-2015277). Informed written consent was obtained from the patients after explaining the purpose and procedures of the study. Confidentiality was strictly maintained throughout the study.

\section{Availability of data and material}

The datasets used and/or analysed during the current study are available from the corresponding author on reasonable request.

\section{Competing interests}

The authors declare that they have no competing interests.

\section{Funding}

Funding for this article has come from personal funds.

\section{Authors' contributions}

KA, LSS, PMS, TYL have made substantial contributions to conception and design; KA, TYL, PMS have made substantial contributions to acquisition of data; MAMI, KA, TYL, CLG have made substantial contributions to analysis and interpretation of data; KA, TYL, CLG, HH, MAM have been involved in drafting the manuscript; LSS, TYL, MAMI, CLG, HH have been involved in revising it critically for important intellectual content; KA, LSS, PMS, TYL, MAMI, CLG, $\mathrm{HH}$ have given final approval of the version to be published.

\section{Acknowledgement}

The authors acknowledge Dr Azuwairie, Dr Zahir fitri and Dr Karyn Lin Wern for their assistance in this study. Special thanks to Serdang Hospital colleagues and nurses who took care of the patients.

\section{References}

1. Ingsathit A, Thakkinstian A, Chaiprasert A, Sangthawan P, Gojaseni P, et al. (2010) Prevalence and risk factors of chronic kidney disease in the Thai adult population: Thai SEEK study. Nephrol Dial Transplant 25: 1567-1575. [Crossref]

2. Chen N, Wang W, Huang Y, Shen P, Pei D, et al. (2009) Community-based study on CKD subjects and the associated risk factors. Nephrol Dial Transplant 24: 2117-2123. [Crossref]

3. Ong-Ajyooth L, Vareesangthip K, Khonputsa P, Aekplakorn W (2009) Prevalence of chronic kidney disease in Thai adults: a national health survey. BMC Nephrol 10: 35. [Crossref] 
4. Centers for Disease Control and Prevention (CDC) (2007) Prevalence of chronic kidney disease and associated risk factors--United States, 1999-2004. MMWR Morb Mortal Wkly Rep 56: 161-165. [Crossref]

5. Lim YN, Ong LM, Goh BL (2011)18th Report of the Malaysian Dialysis and Transplant Registry 2011. National Renal Registry.

6. Brescia MJ, Cimino JE, Appel K, Hurwich BJ (1966) Chronic hemodialysis using venipuncture and a surgically created arteriovenous fistula. N Engl J Med 275: 10891092. [Crossref]

7. Malovrh M (2006) Strategy for the maximal use of native arteriovenous fistulae for hemodialysis. Scientific World Journal 6: 808-815. [Crossref]

8. Irish A, Dogra G, Mori T, Beller E, Heritier S, et al. (2009) Preventing AVF thrombosis: The rationale and design of the Omega-3 fatty acids (Fish Oils) and Aspirin in Vascular access outcomes in renal Disease (FAVOURED) study. BMC Nephrol 10:1.

9. Asif A, Roy-Chaudhury P, Beathard GA (2006) Early arteriovenous fistula failure: a logical proposal for when and how to intervene. Clin J Am Soc Nephrol 1: 332-339. [Crossref]

10. Ravari H, Kazemzade GH, Sarookhani A, Khashayar P (2008) Effect of heparin on the patency of arteriovenous fistula. Acta Medica Iranica 46: 379-382.

11. Ebrahimifard F (2015) Effect of intra operative intravenous injection of heparin on patency rate of radio cephalic autogenous arteriovenous-fistula in chronic renal failure patients. Arch Crit Care Med 1: e1528.

12. D'Ayala M, Smith RM, Martone C, Briggs W, Deitch JS, et al. (2008) The effect of systemic anticoagulation in patients undergoing angioaccess surgery. Ann Vasc Surg 22: $11-15$.

13. Bhomi KK, Shrestha S, Bhattachan CL (2008) Role of systemic anticoagulation in patients undergoing vascular access surgery. Nepal Med Coll J 10: 222-224.

14. Rollo HA, Maffei FH, Yoshida WB, Lastória S, Curi PR, et al. (1991) Heparin, heparin plus ASA and dipyridamole, and arteriovenous fistula as adjuvant methods to prevent rethrombosis after venous thrombectomy. Experimental study in rabbits. Int Angiol 10: 88-94.
15. Silva MB, Hobson RW, Pappas PJ, Jamil Z, Araki CT, et al. (1998) A strategy for increasing use of autogenous hemodialysis access procedures: impact of preoperative noninvasive evaluation. J Vasc Surg 27: 302-308.

16. Huber TS, Ozaki CK, Flynn TC, Lee WA, Berceli SA, et al. (2002) Prospective validation of an algorithm to maximize native arteriovenous fistulae for chronic hemodialysis access. J Vasc Surg 36: 452-459.

17. Mendes RR, Farber MA, Marston WA, Dinwiddie LC, Keagy BA, et al. (2002) Prediction of wrist arteriovenous fistula maturation with preoperative vein mapping with ultrasonography. J Vasc Surg 36: 460-463. [Crossref]

18. Smith GE, Gohil R, Chetter IC (2012) Factors affecting the patency of arteriovenous fistulas for dialysis access. $J$ Vasc Surg 55: 849-855. [Crossref]

19. Nguyen TH, Bui TD, Gordon IL, Wilson SE (2007) Functional patency of autogenous AV fistulas for hemodialysis. $J$ Vasc Access 8: 275-280. [Crossref]

20. Fan PY, Schwab SJ (1992) Vascular access: concepts for the 1990s. J Am Soc Nephrol 3: 1-11. [Crossref]

21. Bergqvist D, Siegbahn A (1993) Effects of heparin on the vessel wall and blood cellular elements. Vasc Med Rev 4: 221-233.

22. Farrokhyar F, Farrokhyar F, Karanicolas PJ, Thoma A, Simunovic M, et al. (2010) Randomized controlled trials of surgical interventions. Ann Surg 251: 409-416.

23. Wang BR, Rowe VL, Ham SW (2010) A prospective clinical evaluation of the effects of intraoperative systemic anticoagulation in patients undergoing arteriovenous fistula surgery. Am Surg 76: 1112-1114.

24. Smith GE, Souroullos P, Cayton T, Harwood A, Carradice D, et al. (2016) A systematic review and meta-analysis of systemic intraoperative anticoagulation during arteriovenous access formation for dialysis. $J$ Vasc Access 17: 1-5.

Copyright: $₫ 2017$ Aimanan K. This is an open-access article distributed under the terms of the Creative Commons Attribution License, which permits unrestricted use, distribution, and reproduction in any medium, provided the original author and source are credited. 